\title{
OS PROGRAMAS DE PATENTES VERDES FRENTE AO DESENVOLVIMENTO SUSTENTÁVEL
}

\begin{abstract}
Alessandra Vanessa Teixeira*
RESUMO

O presente artigo tem como objetivo avaliar os programas de patentes verdes e sua contribuição para a implementação dos objetivos do desenvolvimento sustentável, examinando os principais programas de patentes verdes no mundo, com especial atenção ao programa de patentes verdes no Brasil. $O$ estudo proposto refere-se à pesquisa básica, que tem como base lógica operacional o método dedutivo e a abordagem qualitativa. Nesse sentido, a pesquisa parte da análise geral do sistema de patentes, seguida pela análise de suas particularidades sobretudo no que corresponde à proteção das tecnologias verdes por meio do programa de patentes verdes.
\end{abstract}

Palavras-chave: Desenvolvimento Sustentável; Objetivos do Desenvolvimento Sustentável; Patentes Verdes; Sustentabilidade; Tecnologias Verdes.

\section{GREEN PATENT PROGRAMS ADDRESSING SUSTAINABLE DEVELOPMENT}

\begin{abstract}
This paper aims to evaluate green patent programs and their contribution to the implementation of sustainable development objectives by examining the main green patent programs in the world, with particular attention to the green patent program in Brazil. The proposed study refers to basic research, based on the operational logic of the deductive method and the qualitative approach. In this sense, the research is based on the general analysis of the patent system, followed by an analysis of its particularities, particularly in relation to the protection of green technologies through the green patent program.
\end{abstract}

Keywords: Sustainable development; Sustainable Development Objectives; Green Patents; Sustainability; Green Technologies.

\section{Introdução}

Os Programas Patentes Verdes vieram trazer importantes contribuições para o desenvolvimento sustentável em âmbito global, já que com o implemento desses programas, a obtenção de uma patente relativa a uma invenção é mais rápida, o que

\footnotetext{
* Doutoranda em Ciência Jurídica pela Universidade do Vale do Itajaí - UNIVALI. Mestra em Direito pela Universidade de Passo Fundo - UPF. Especialista em Direito Público pela Faculdade Meridional IMED. Bacharel em Direito pela Universidade de Passo Fundo - UPF. Advogada OAB/RS 87583. Bolsista Capes-taxa. Endereço Postal: Rua Plácido de Castro, 989, Bairro Lucas Araújo, Passo Fundo/RS, CEP 99074-245. Endereço Eletrônico: alessandra.sp@ hotmail.com
} 
significa que a sua comercialização será mais rápida também, bem como a oportunidade de difundir-se globalmente, possibilitando que um invento alcance um efeito poderoso contra a eliminação e mitigação dos problemas ambientais que acabam por travar o desenvolvimento sustentável.

Diante disso, o presente artigo tem por objetivo avaliar se os programas de patentes verdes contribuem para a implementação dos objetivos do desenvolvimento sustentável, examinando os principais programas de patentes verdes no mundo, com especial atenção ao programa piloto de patentes verdes no Brasil, e aportando contribuições para eventual aperfeiçoamento desse programa, considerando as contribuições das patentes verdes para o desenvolvimento sustentável.

\section{Os programas de patentes verdes no mundo}

Os programas de patentes verdes tiveram impulso com o chamado da Organização das Nações Unidas (ONU), que, no ano de 2008, por meio de seu Secretário-Geral Sr. Ban Ki-Moon, solicitou da Organização Mundial da Propriedade Intelectual (OMPI) mais empenho e intervenção no tocante ao papel da tecnologia e do desenvolvimento industrial em relação às mudanças climáticas, afim de que os paísesmembros da OMPI se harmonizassem quanto aos conceitos de tecnologias verdes, buscando alternativas que pudessem melhorar os problemas ambientais.

Como resultado do apelo feito pela ONU, no ano de 2009, países desenvolvidos como o Reino Unido, Austrália, Coréia do Sul, Japão, Estados Unidos e Israel, por meio de seus escritórios de Propriedade Industrial, implementaram programas pilotos de patentes verdes, cujo principal objetivo seria a aceleração e prioridade no exame de patentes referentes a tecnologias verdes. (SANTOS; OLIVEIRA, 2016)

Segundo Eric L. Lane (2012), as solicitações de patentes relacionadas a tecnologias verdes são adiantadas, fora da sua vez, para um processamento e exame acelerado, reduzindo consideravelmente o tempo que se leva para obter uma patente de invenção, o que permite que tal tecnologia se espalhe por diferentes países mais rapidamente para, assim, fazer frente às mudanças climáticas e a outros problemas relacionados ao meio ambiente.

A implementação de programas de patentes verdes no mundo é algo novo, 
tendo em vista que remontam o ano de 2009, dando-se de forma gradativa. Primeiramente no Reino Unido (2009), seguido por Austrália (2009), Coréia do Sul (2009), Japão (2009), Estados Unidos (2009), Israel (2009), Canadá (2011), Brasil (2012), China (2012) e Taiwan (2014). Esses programas são abordados neste tópico, salvo o caso brasileiro que se trata no tópico seguinte.

O Reino Unido foi o primeiro a implementar o Programa de Patentes Verdes, o qual foi anunciado pelo Ministro de Propriedade Intelectual do Reino Unido à época, David Lammy, mediante declaração ${ }^{1}$ em 12 de maio de 2009. (CHUGÁ PORRAS, 2015)

Segundo Antoine Dechezleprêtre, o Programa de Patentes Verdes do Reino Unido foi implementado em maio de 2009, no contexto da preparação para a Conferência das Nações Unidas sobre as Alterações Climáticas (UNFCCC) em Copenhagen, que deveria dar origem ao sucessor do Protocolo de Quioto. Para ter sua patente considerada para exame acelerado, o requerente deve apresentar uma carta explicando por que a invenção é ambientalmente amigável. O escritório de propriedade intelectual do Reino Unido (UKIPO) não exige evidências para esta "amizade ambiental", mas afirma que vai rejeitar invenções claramente inadequadas. Não há nenhuma exigência de processo formal para a patente e nenhuma taxa adicional é necessária. De acordo com o UKIPO, as patentes podem ser esperadas para ser concedidas em nove meses, em comparação com dois a três anos para o procedimento de exame normal. (DECHEZLEPRÊTRE, 2013)

Além disso, Eric L. Lane refere que o requerente da patente pode escolher qual a fase processual gostaria de acelerar a aplicação: a pesquisa (busca); o exame de patenteabilidade; a combinação de ambos (pesquisa e exame); e/ou a publicação. (LANE, 2011)

\footnotetext{
${ }^{1}$ David Lammy disse: "As mudanças climáticas afetam a todos e todas as ações que tomamos agora para melhorar a tecnologia de baixa emissão de carbono tem que ser positiva, tanto para o ambiente como para a nossa futura competitividade econômica. Nós já demos grandes passos adiante no automobilismo mais verde, apoiando o desenvolvimento de novos veículos e incentivando os motoristas a fazer escolhas mais ecológicas. A iniciativa de hoje se baseia nisso, oferecendo às empresas inovadoras do Reino Unido, trabalhando em tecnologias verdes, a chance de obter direitos de patente de alta qualidade mais rápido do que nunca, o que acelerará o tempo necessário para colocar os produtos no mercado, beneficiando tanto as empresas quanto os consumidores. (tradução nossa) INTELLECTUAL PROPERTY OFFICE (United Kingdom), UK 'Green'inventions to get fast-tracked through patente system, http://www.ipo.gov.uk/about/press/press-release/press-release-2009/press-release-20090512.htm, 12 de janeiro de 2017.
} 
Entre maio de 2009 e junho de 2012 o Programa de Patentes Verdes do Reino Unido teve 776 pedidos acelerados ${ }^{2}$. O tipo de tecnologia coberta pelo Programa correspondia a todas as invenções ambientalmente amigáveis. (REIS, 2013)

O programa australiano de patentes verdes começou em setembro de 2009. Como no Reino Unido, não existe uma definição formal do que constitui uma patente verde. O candidato deve simplesmente fornecer uma declaração de que a tecnologia tem alguns benefícios ambientais. $\mathrm{O}$ exame dos pedidos no âmbito do programa deverá começar dentro de quatro a oito semanas após a apresentação do pedido de exame acelerado e nenhuma taxa adicional é necessária. (DECHEZLEPRÊTRE, 2013)

De acordo com o escritório de propriedade industrial da Austrália (INTELLECTUAL PROPERTY OFFICE AUSTRALIA, 2017), a mudança climática e o seu impacto global é um dos maiores desafios do século XXI. Sabendo que a tecnologia e a inovação desempenham um papel fundamental na capacidade de todos de geri-la eficazmente, passaram a ajudar os inovadores verdes a encontrarem uma via rápida para o mercado, oferecendo prioridade às tecnologias ambientalmente amigáveis no sistema de pedidos de patentes. Esta iniciativa oferece invenções ambientalmente benéficas, sendo uma forma de chegar aos consumidores rapidamente.

Entre setembro de 2009 e agosto de 2012 o Programa de Patentes Verdes da Austrália teve 43 pedidos acelerados. O tipo de tecnologia coberta pelo Programa correspondia a todas as invenções ambientalmente amigáveis. (REIS, 2013)

Em outubro de 2009, o Escritório Coreano de Propriedade Intelectual (KIPO) lançou um "sistema de exame superacelerado para tecnologia verde". A KIPO afirma que uma ação no primeiro escritório será emitida no prazo de um mês após o pedido. Ao contrário do Reino Unido e da Austrália, apenas as tecnologias financiadas ou acreditadas pelo governo coreano - ou mencionadas nas leis ambientais relevantes do governo - são elegíveis para tratamento acelerado sob o sistema de exame super acelerado. Tecnologias para as quais todos os requerentes podem solicitar o exame acelerado incluem prevenção de ruído, qualidade da água, prevenção da poluição do ar, eliminação de resíduos, gestão de resíduos de gado, reciclagem e esgoto. Outras tecnologias verdes, incluindo energia renovável, redução de emissões de carbono, transporte eficiente de energia e led's são elegíveis somente se a invenção tiver

2 Para consultar os pedidos de patentes verdes do Reino Unido: https://www.ipo.gov.uk/pgcp?lastResult $=0 \&$ perPage $=10 \&$ filter $=\&$ sort $=\mathrm{GCP}+$ Request + Date\#starttabs Acesso em 26 de fevereiro de 2017. 
"recebido apoio financeiro ou certificação do governo". (DECHEZLEPRÊTRE, 2013)

Então, de acordo com o Relatório Anual de 2009 do KIPO, o sistema, que foi pesquisado e desenvolvido de acordo com a estratégia nacional de baixo carbono, crescimento verde, é limitado a tecnologias que são classificadas como verdes pelo governo (sob a forma de ajuda financeira ou de certificação) ou designadas em leis ambientais. Outros pré-requisitos para um exame super acelerado incluem um relatório de pesquisa da técnica anterior de uma das organizações designadas de pesquisa da arte anterior e uma declaração da finalidade do exame super acelerado no formulário de pedido. Entre outubro e dezembro de 2009, foram apresentados 52 pedidos e os resultados dos exames foram apresentados no prazo de um mês, salvo em alguns casos que não satisfaziam os requisitos do exame super acelerado. $\mathrm{O}$ caso mais rápido demorou apenas 18 dias. A aceleração da tecnologia verde desta forma é especialmente benéfica à luz das preocupações ambientais. (KOREAN INTELLECTUAL PROPERTY OFFICE, 2017)

Entre outubro de 2009 e junho de 2012 o Programa de Patentes Verdes da Coréia do $\mathrm{Sul}^{3}$ teve 604 pedidos acelerados. O tipo de tecnologia coberta pelo Programa correspondia àquelas capazes de minimizar a emissão de dióxido de carbono e outros poluentes, financiadas ou credenciadas pelo governo coreano ou mencionadas em relevantes leis ambientais do governo sul-coreano. (REIS, 2013)

O Serviço de Patentes do Japão (JPO) (JAPAN PATENT ATTORNEYS ASSOCIATION, 2017) lançou o seu programa para acelerar o exame das "aplicações relacionadas com a tecnologia verde" em novembro de 2009. As tecnologias devem ser de um tipo "que tem um efeito de poupança de energia e contribui para a redução de $\mathrm{CO} 2$ ", fornecer ao escritório de patentes "uma breve descrição que explica que a invenção reivindicada tem uma vantagem na redução do consumo, redução de $\mathrm{CO} 2$ e semelhantes" e deve conduzir uma pesquisa da técnica anterior e uma comparação da invenção reivindicada com a mais próxima prioridade da arte. Isso transfere parte do trabalho do escritório de patentes para o requerente da patente. No âmbito do programa, os candidatos devem receber uma ação no primeiro escritório em cerca de dois meses.

3 Para mais informações referentes ao Programa de Patentes Verdes da Coréia do Sul: http://www.kipo.go.kr/kpo/user.tdf?a=user.english.html.HtmlApp\&c=100002\&catmenu=ek02_01_02_03 $\mathrm{e}$

http://www.kipo.go.kr/kpo/user.tdf?a=user.english.html.HtmlApp\&c=100000\&catmenu=ek02_01_02_01 Acesso em: 25 de fevereiro de 2017. 
(DECHEZLEPRÊTRE, 2013)

Entre novembro de 2009 e dezembro de 2012 o Programa de Patentes Verdes do Japão teve 220 pedidos acelerados. O tipo de tecnologia coberta pelo Programa correspondia àquelas que tem um efeito na conservação de energia e contribuem para a redução de $\mathrm{CO} 2$, além dos pedidos que tem impacto na economia de recursos e na redução dos impactos ambientais. (REIS, 2013)

O Escritório de Patentes e Marcas dos Estados Unidos lançou um Programa Piloto de Tecnologia Verde em novembro de 2009, entrando em vigência em dezembro do mesmo ano. Inicialmente, o programa estava limitado a aplicações que se enquadravam em um dos códigos da US Patent Classification (USPC) considerados para cobrir "tecnologias verdes". Essas classes de tecnologia USPC incluíam produção de energia alternativa, conservação de energia, agricultura ambientalmente amigável e purificação ambiental, proteção e remediação. No entanto, após alguns meses, o USPTO percebeu que a exigência de classificação era muito restritiva e decidiu substituí-la por uma simples declaração de por que a invenção abrange uma "tecnologia verde". Isso pode incluir aplicações relacionadas à qualidade ambiental, conservação de energias renováveis, redução das emissões de gases com efeito de estufa (UNITED STATES PATENT AND TRADEMARK OFFICE - USPTO, 2010). Além desses requisitos, o USPTO também impõe algumas restrições ao número de reivindicações feitas na patente. O exame das candidaturas aceitas para o Green Technology Pilot começa imediatamente, em vez de ter que esperar por dois a três anos. (DECHEZLEPRÊTRE, 2013)

Entre dezembro de 2009 e março de 2012, então, o Programa de Patentes Verdes dos Estados Unidos teve 3.533 pedidos acelerados. O tipo de tecnologia coberta pelo Programa correspondia àquelas que se referiam à qualidade ambiental, conservação de energia, desenvolvimento dos recursos energéticos renováveis ou tecnologias de redução de emissões de gases de efeito estufa. (REIS, 2013)

O Programa de Patentes Verdes de Israel foi lançado em dezembro de 2009. O Escritório de Patentes de Israel permitiu que as patentes verdes fossem submetidas a exame prioritário, um procedimento geralmente disponível apenas quando se suspeita de infração. O requisito do assunto é muito amplo: para solicitar um exame acelerado, o requerente deve simplesmente fornecer uma explicação de por que o invento ajuda a avançar na proteção ambiental. As taxas suplementares normalmente exigidas para 
exame prioritário não são necessárias para as patentes ecológicas. Após a qualificação no âmbito do programa, estes pedidos de patente verde são examinados no prazo de três meses. (DECHEZLEPRÊTRE, 2013)

De acordo com o escritório de propriedade industrial de Israel, as aplicações verdes são aplicações nas quais a invenção descrita ajuda a melhorar o ambiente, impedindo as causas do aquecimento global, reduzindo a poluição do ar ou da água, promovendo a agricultura não poluente, e as relacionadas com fontes de energia alternativas, etc. A ILPO publicou uma Circular (MN 76 de 13 de dezembro de 2009) em que foram publicados critérios de elegibilidade para a expedição do exame de "aplicação verde". Uma aplicação que satisfaça os critérios da Circular será classificada como uma invenção verde e seu exame deve começar dentro de 3 meses da data de classificação. É possível solicitar a classificação "verde" de um pedido que já foi apresentado como um pedido regular e cujo exame ainda não começou. Não há nenhuma taxa associada a este pedido. (ISRAEL PATENT OFFICE, 2017)

Entre dezembro de 2009 e setembro de 2012, então, o Programa de Patentes Verdes de Israel teve 78 pedidos acelerados. O tipo de tecnologia coberta pelo Programa correspondia àquelas cuja comercialização ajuda a resolver ou mitigar os impactos ambientais ou consertar o meio ambiente e os recursos naturais. (REIS, 2013)

O Instituto Canadense de Propriedade Intelectual (CIPO) lançou seu programa acelerado para pedidos de patentes verdes em março de 2011. Para se beneficiar do programa, os candidatos devem fazer uma declaração informando que a invenção poderia "ajudar a resolver ou mitigar impactos ambientais negativos ou ajudar a conservar o ambiente natural". Não há necessidade de taxa adicional. No âmbito do programa acelerado, o requerente receberá uma ação de primeiro escritório no prazo de dois meses, em vez de dois a três anos. (DECHEZLEPRÊTRE, 2013)

A iniciativa do Escritório Canadense de Propriedade Intelectual (CIPO) para agilizar o exame de pedidos de patente relacionados com tecnologia verde entrou em vigor em 3 de março de 2011 e foi publicada na Gazeta do Canadá, Parte II ${ }^{4}$. Acelerar o processamento de pedidos de patentes relacionados a tecnologias ambientais (verdes) dentro do sistema canadense de propriedade intelectual estimulará o investimento e acelerará a comercialização de tecnologias que poderiam ajudar a resolver ou mitigar os

\footnotetext{
${ }^{4}$ Ver http://www.gazette.gc.ca/rp-pr/p2/2011/2011-03-16/html/sor-dors61-eng.html
} 
impactos ambientais ou a conservar o ambiente natural e os recursos. Nenhuma taxa adicional é necessária para avançar o exame de pedidos de patentes relacionadas com tecnologias verdes. A aceitação de um pedido de exame acelerado no âmbito deste serviço proposto destina-se apenas a permitir o rápido julgamento de pedidos específicos e não é um endosso do governo de qualquer patente em particular. (CANADIAN INTELLECTUAL PROPERTY OFFICE, 2017)

Assim, entre março de 2011 e agosto de 2012, então, o Programa de Patentes Verdes do Canadá teve 67 pedidos acelerados. O tipo de tecnologia coberta pelo Programa deveria ajudar a preservar/melhorar a qualidade do meio ambiente, mitigar fatores de aquecimento global, reduzir a poluição do ar ou da água, promover agricultura não poluidora, economizar energia, facilitar reciclagem, aprimorar o manejo de recursos, etc. (REIS, 2013)

O Escritório de Propriedade Intelectual do Estado da China $^{5}$ lançou um programa de patentes verdes em agosto de 2012. As tecnologias elegíveis devem estar relacionadas à poupança de energia, proteção ambiental, energia nova, veículos de energia nova, tecnologia de baixo carbono e tecnologia de economia de recursos. $\mathrm{O}$ programa patentes verdes também abrange algumas tecnologias não-ambientais que são consideradas cruciais para o desenvolvimento econômico da China: nova geração de tecnologia da informação, biologia, fabricação de equipamentos high-end e novo material. Os requerentes de patentes devem fornecer um relatório de pesquisa juntamente com o pedido de exame acelerado. As candidaturas aceitas ao abrigo do programa serão examinadas no prazo de um ano após a aprovação do pedido. (DECHEZLEPRÊTRE, 2013)

De acordo com a Intellectual Asset Management (IAM, 2017), para incentivar o desenvolvimento de tecnologias verdes, o Escritório de Propriedade Intelectual de Taiwan (TIPO) ${ }^{6}$ incluiu aplicações de patentes de tecnologia verde no Programa de Exame Acelerado (AEP). A partir de 1 de Janeiro de 2014, os pedidos de patentes de tecnologia verde tiveram direito a um exame acelerado se o requerente apresentasse um pedido de AEP.

Da análise dos programas de patentes verdes existentes e abordados neste tópico, observa-se a aceleração na difusão do conhecimento tecnológico em tecnologias

\footnotetext{
${ }^{5}$ Ver http://www.wipo.int/wipolex/en/details.jsp?id=13322

${ }^{6}$ Ver https://www.tipo.gov.tw/ct.asp?xItem $=332597 \& c t$ Node $=6817 \& \mathrm{mp}=2$
} 
verdes a curto prazo. Ademais, na maioria dos países, para que uma patente de invenção entre no programa de patentes verdes, não é cobrada nenhuma taxa adicional, bastando uma simples petição do solicitante e um breve resumo de seu invento, para que seja incluído no mencionado programa.

\section{0 programa brasileiro de patentes verdes}

Com base em programas semelhantes adotados em outros países, o Instituto Nacional de Propriedade Industrial (INPI) propôs um projeto prioritário que se chama "Patente Verde", através do qual uma tecnologia voltada para o meio ambiente terá seu pedido analisado de forma mais rápida. O objetivo principal desse projeto, então, é acelerar o exame da tecnologia "verde", visando dar um privilégio especial para os setores tecnológicos que estão buscando soluções boas para o meio ambiente brasileiro ou mundial.

O programa Patentes Verdes tem como objetivo contribuir para as mudanças climáticas globais e visa a acelerar o exame dos pedidos de patentes relacionados a tecnologias voltadas para o meio ambiente (Resoluções PR $\mathrm{n}^{\circ}$ $\underline{131 / 2014}$ e PR n $\left.^{\circ} 145 / 2015\right)$. Com esta iniciativa, o INPI também possibilita a identificação de novas tecnologias que possam ser rapidamente usadas pela sociedade, estimulando o seu licenciamento e incentivando a inovação no país. (INSTITUTO NACIONAL DE PROPRIEDADE INDUSTRIAL INPI, 2016)

O programa "Patentes Verdes", então, trata-se de um programa piloto, o qual tem como principal objetivo reunir e acelerar o exame de pedidos de patentes que contemplem inovações relacionadas ao meio ambiente, identificando novas tecnologias para o desenvolvimento sustentável. (RICHTER, 2014)

O Programa Piloto "Patentes Verdes" brasileiro foi criado por meio da Resolução PR 283/2012 ${ }^{7}$ do INPI, a qual disciplinou o exame prioritário de pedidos de Patentes Verdes, bem como os procedimentos relativos ao Programa Piloto. Além disso, a partir dela ficou definido que os pedidos de patentes verdes seriam aqueles "pedidos de patentes com foco em tecnologias ambientalmente amigáveis ou ditas tecnologias

\footnotetext{
${ }^{7}$ Revogada pela Resolução PR No 75, de 18 de março de 2013, atualmente estando vigente a Resolução $\mathrm{n}^{\mathrm{o}} 131$ de 15 de abril de 2014.
} 
verdes, sendo tais tecnologias dispostas e apresentadas em um inventário publicado pela Organização Mundial da Propriedade Intelectual - OMPI”.

Como objetivos, buscou-se estimular o desenvolvimento de soluções que contribuíssem para as mudanças climáticas globais e acelerar o exame dos pedidos de patentes relacionados a tecnologias verdes, já que previa análise prioritária. De acordo com a referida resolução, o programa piloto tinha validade até 02 de abril de 2013 ou até que atingisse 500 solicitações concedidas, o que viesse a ocorrer primeiro. Ainda, deveria apresentar alguns requisitos: ser um pedido de patente de invenção, ter sido depositado a partir de janeiro de 2011 e estar relacionado à tecnologia verde. Essa foi a $1^{\text {a }}$ Fase do Programa Patentes Verdes.

De acordo com Antoine Dechezleprêtre (2013), o Brasil foi a primeira economia emergente a lançar um programa de exame acelerado de patentes verdes. As tecnologias verdes elegíveis se enquadrariam nas seguintes categorias: energia alternativa, transporte, conservação de energia, gestão de resíduos e agricultura. O objetivo do programa, desde o início, foi reduzir o período de exame de pedidos de patentes relacionadas a tecnologias verdes a menos de dois anos. O tempo médio de exame no Brasil é de cinco anos e quatro meses.

Após a criação do Programa, que se deu em 2012, e com o prazo de validade expirando, o INPI, por meio de Resolução, decidiu prorrogar e expandir o programa de exame prioritário de pedidos de Patentes Verdes até 16 de abril de 2014 ou até 500 solicitações concedidas. Esse período ficou definido como a $2^{\mathrm{a}}$ Fase do Programa Patentes Verdes.

No ano de 2014, publicou-se mais uma Resolução com a mesma finalidade e sem nenhuma alteração quanto ao conteúdo, apenas prorrogando o programa por mais um ano, até 16 de abril de 2015 ou até que se atingissem 500 solicitações concedidas, o que ocorresse primeiro. Tal período ficou definido como a $3^{\mathrm{a}}$ Fase do Programa Patentes Verdes.

Em 2015 o INPI, também por meio de Resolução, considerando que a proteção dos direitos relativos à propriedade industrial, o seu interesse social e o desenvolvimento tecnológico e econômico do País, efetua-se mediante a concessão de 
patentes, decidiu alterar o prazo concedido para a $3^{\text {a }}$ Fase do Programa Patentes Verdes para 16 de abril de $2016 .{ }^{8}$

Durante a vigência da $3^{\text {a }}$ Fase do Programa (17/04/2014 a 16/04/2016) segundo arquivo de dados de acompanhamento divulgados em 14 de julho de 2015, pelo INPI, até esta data havia um total de 150 pedidos ingressantes (isso relativo à $3^{\mathrm{a}}$ fase). Por meio desse arquivo, pode-se visualizar, também, que desde a $1^{\text {a }}$ Fase do Programa, 218 pedidos haviam sido considerados aptos, dos quais naquela data, 52 pedidos deferidos, 56 indeferidos, 2 arquivados e 33 não aptos.

Segundo Patricia Carvalho dos Reis (et. Al.), em estudo realizado no ano de 2013, o Programa Brasileiro de Patentes Verdes apresenta, desde o seu princípio, como principais objetivos:

\begin{abstract}
Acelerar o exame de pedidos que se enquadram nas definições adotadas para tecnologias verdes e na Legislação Vigente; visam maximizar o apoio a invenções que poderiam ter um impacto nas mudanças climáticas; oferecem às empresas inovadoras em tecnologias verdes a chance de obter patentes em menos tempo, traduzindo-se em maior segurança jurídica durante negociações; criar guias para orientação ao desenvolvimento da indústria nacional; incentivar ao desenvolvimento, à transferência de tecnologia e à comercialização de Tecnologias Verdes no Brasil; estimular à pesquisa e ao desenvolvimento científico doméstico das tecnologias verdes; propiciar segurança jurídica ao depositante em mesas de negociação. (2013, p. 9)
\end{abstract}

Após a conclusão da $3^{\text {a }}$ Fase, o Programa Piloto Patentes Verdes foi suspenso para avaliação de resultados ${ }^{9}$. Logo depois, o INPI decidiu tornar o serviço permanente, noticiando que:

\begin{abstract}
Após quatro anos na modalidade de programa-piloto, o exame prioritário "Patentes Verdes" passou a ser um serviço permanente do INPI, desde o dia 6 de dezembro, devido aos bons resultados alcançados. Dos 480 pedidos que deram entrada durante a vigência do programa-piloto, 325 foram considerados aptos, sendo 112 pedidos deferidos e 115 indeferidos, até setembro de 2016. O tempo máximo dessas decisões foi de cerca de dois anos.
\end{abstract}

O Programa atual, então, por meio da Resolução 175/2016, disciplina o exame prioritário de pedidos de "Patente Verde". Tal norma traz o conceito de "Patente Verde"

\footnotetext{
${ }^{8}$ Vide: http://www.inpi.gov.br/noticias/titulo-da-noticia-entre-35-e-90-caracteres-com-espaco

${ }^{9}$ Vide: http://www.inpi.gov.br/comunicados/patentes-verdes-esta-temporariamente-suspenso
} 
como aquele "pedido de patente considerado apto ao exame prioritário, conforme listagem apresentada no Anexo I desta Resolução".

Nas Resoluções anteriores, que disciplinavam o Programa Piloto, não havia o conceito de "Patente Verde", mas sim o que seriam os "pedidos de Patente Verde". Portanto, o conceito normativo de Patente Verde se deu por meio da normativa de 2016. Os demais aspectos permanecem os mesmos, inclusive quanto a listagem de tecnologias verdes, que é a mesma desde a criação do Projeto Piloto Patentes Verdes.

As patentes verdes, então, são categorizadas por meio da listagem de tecnologias verdes, a qual tem por base o inventário da OMPI, sendo divididas entre energias alternativas, transportes, conservação de energia, gerenciamento de resíduos e agricultura.

Portanto, para participar do Programa Patentes Verdes do INPI o titular deve enquadrar sua inovação em uma das categorias acima referidas, requisitando a inscrição por meio de petição própria e mediante o pagamento de retribuição específica, indicando os dados do pedido prioritário de patente. ${ }^{10}$

Destaca-se que não há requisitos técnicos diferenciados nas patentes verdes, o que se tem é que indicar que se trata de pedido prioritário envolvendo tecnologia ambientalmente amigável, que esteja elencada no rol de tecnologias verdes do INPI. Embora não tenha exigências técnicas específicas em relação a redação do relatório descritivo, as patentes verdes, de certo modo, necessitam destacar como as tecnologias contribuem para o desenvolvimento sustentável.

Nesse sentido, ao analisar o Programa Piloto de Patentes Verdes do INPI, em 2013, Patricia Carvalhos dos Reis (et. Al.) concluiu que

\begin{abstract}
Apesar de buscar promover a competitividade no setor de tecnologia verde, o Programa de Patentes Verdes do INPI pode ser extremamente benéfico à sociedade, à medida que é implementado, através do programa, a aceleração do exame técnico referente às Tecnologias Verdes. Sendo vantajoso, pois este programa estabelece um cronograma ambicioso para a disposição de patentes, e, assim, incentiva os examinadores de patentes para gastar menos tempo em cada aplicação. (2013, p. 16)
\end{abstract}

Portanto, o diferencial estabelecido pelo INPI das patentes verdes em relação às patentes convencionais, está relacionado com o tempo administrativo para análise e

\footnotetext{
${ }^{10}$ Para verificar o passo a passo de como ingressar no Programa Patentes Verdes, seja com pedido novo ou com pedido que já está depositado no INPI, bem como conferir o custo de ingressar no Programa, acesse: http://www.inpi.gov.br/menu-servicos/patente/patentes-verdes-v2.0
} 
concessão ou negativa do pedido patentário. No caso das patentes verdes, o prazo para análise é muito inferior aos pedidos de patentes não verdes. Salienta-se que os requisitos da proteção das patentes verdes são exatamente os mesmo de uma patente normal, bem como os benefícios do inventor, o que ocorre na verdade, no campo nacional, é uma célere análise do pedido e da tramitação administrativa.

Dessa forma, o Programa de Patentes Verdes brasileiro mostra grande potencial como instrumento incentivador da produção de tecnologias verdes, vez que tem cumprido seu objetivo em reduzir o tempo de análise das solicitações de patentes verdes, gerando maiores incentivos à investimentos e inovações na área ambiental pela possibilidade de angariar retornos financeiros de forma mais rápida, por meio da exploração comercial destas tecnologias.

\title{
3 Contribuições das patentes verdes para o desenvolvimento sustentável
}

O desenvolvimento sustentável contempla não apenas a dimensão ambiental, mas também as dimensões social e econômica. Nesse contexto, as tecnologias apresentam um papel fundamental, pois se por um lado "não há sustentabilidade sem inovação" (ALMEIDA, 2007, p. 167), por outro, nem toda inovação é sustentável, já que, conforme assinala Leff:

\begin{abstract}
A sustentabilidade depende de como se extraem e como se transformam os recursos do entorno, o que se produz e como se produz, o que se consome e como se consome; o custo ambiental e a sustentabilidade das formas de satisfazer as necessidades básicas medidas pelos indicadores de qualidade de vida, de bem-estar e de desenvolvimento humano nas cidades devem considerar seu impacto local, no entorno e no nível global. A sustentabilidade depende da construção de uma nova racionalidade global (econômica/ambiental), e não de um equilíbrio entre os custos e benefícios da racionalidade atual. As estratégias de um desenvolvimento urbano sustentável não podem surgir da análise de indicadores atuais de produção e consumo, de seus custos econômicos e desigualdades sociais e de seus impactos ecológicos locais e globais; mas de uma estratégia para gerar fontes alternativas de fornecimento de água e energia que sejam renováveis e não contaminantes; da sustentabilidade da cidade e de seus padrões de consumo no sistema ecológico global. (2001, p. 294)
\end{abstract}

Portanto, as tecnologias devem contribuir com as três dimensões do desenvolvimento sustentável. No entanto, verifica-se que o relatório não exige que se demonstre como a tecnologia contribui para a sustentabilidade, limitando-se às 
reivindicações e ao efeito técnico. Neste caso, percebe-se a necessidade de o efeito técnico (ambiental, econômico e social) das patentes apresentar-se no relatório, evidenciando como ela contribui efetivamente para o desenvolvimento sustentável.

A possibilidade de tecnologias verdes, protegidas por patentes e vinculadas aos programas de patentes verdes existentes no mundo, com base no sistema de patentes, alcançarem a implementação dos objetivos do desenvolvimento sustentável, principalmente no que tange ao objetivo 12, "padrões de produção/consumo sustentáveis", reflete o modo como se quer ver o mundo daqui a alguns anos.

Um sistema que não se preocupa com a esgotabilidade dos recursos naturais, provocando grave degradação ambiental em detrimento do desenvolvimento econômico, está fadado ao comprometimento da sadia qualidade de vida de sua população atual e futura. Logo, as patentes verdes podem incentivar as tecnologias posteriores a tomar como base os avanços ambientais proporcionados. Assim, para que a produção e o consumo sejam mais sustentáveis, as tecnologias que os antecedem também devem ser sustentáveis. Este é um exemplo de outras tecnologias que podem contribuir para o meio ambiente e que não estão no rol da "lista de tecnologias verdes" do INPI.

Outro aspecto importante como contribuição para o Programa Patentes Verdes é em relação ao mecanismo diferenciado de licenciamento. O Objetivo 17 da Agenda 2030, mostra-se como um exemplo de mecanismo de licenciamento diferenciado para promover parcerias. O referido Objetivo "Fortalecer os meios de implementação e revitalizar a parceria global para o desenvolvimento sustentável" traz, como um dos caminhos para efetiva-lo, a tecnologia, e dispõe nesse sentido:

17.7 Promover o desenvolvimento, a transferência, a disseminação e a difusão de tecnologias ambientalmente corretas para os países em desenvolvimento, em condições favoráveis, inclusive em condições concessionais e preferenciais, conforme mutuamente acordado. (grifo nosso) (ONU, 2016, p. 36)

Além do Objetivo 17, outro exemplo de mecanismo de licenciamento são as licenças FRAND (significa equidade, boa fé - condições reais e compatíveis com os parâmetros de mercado). As licenças FRAND se destinam a evitar que a clausura tecnológica, possibilite aos titulares das patentes abusarem de sua posição uma vez que o padrão seja implantado. Tais licenças, além de ofertadas publicamente, serem 
equitativas e de boa fé, também podem ser gratuitas; mas cabe ao solicitante fixar a gratuidade ou a onerosidade do que é ofertado (BARBOSA, 2017). Portanto, são licenciamentos com condições justas, razoáveis e não-discriminatórias para que toda a indústria possa usufruir da tecnologia padrão, para que o mercado evolua. Quem criou a tecnologia pode cobrar para licenciá-la, desde que não seja de forma abusiva.

Além desses dois exemplos de mecanismos especiais de licenciamento, ainda há o licenciamento via ECO PC. Em um estudo no qual analisam a inovação e a difusão de tecnologias verdes via Eco PC (patent commons) ${ }^{11}$, Hall e Helmers questionam se as empresas estão colocando patentes pouco valiosas à disposição de interessados, livres de licenciamento, apenas visando publicidade positiva, e se o licenciamento voluntário sem pagamento de royalties pode ser um caminho para difusão de tecnologias ambientalmente favoráveis. A conclusão btida foi a de que as patentes inscritas no Eco PC são mais valiosas que a média das patentes protegidas pelas respectivas empresas titulares, mas que além de não retratarem inovações radicais, normalmente não compõem o portfólio de tecnologia das empresas licenciantes. Talvez por tal motivo sejam colocadas à disposição para o uso por terceiros, já que não afeta a lucratividade de tais empresas. (HALL; HELMERS, 2011)

A resposta dos autores para a questão da influência do licenciamento voluntário de patentes para a adoção de tecnologias verdes é menos conclusiva, mas sugere que não há impacto considerável na difusão de conhecimento pelo licenciamento gratuito de patentes. Essa conclusão ainda é preliminar dado o curto espaço de tempo entre a concessão das patentes e sua oferta de licenciamento gratuito pelas detentoras das tecnologias envolvidas. (HALL; HELMERS, 2011)

A difusão e a transferência de patentes relacionadas à tecnologia ambientalmente saudável é de vital importância, uma vez que uma criação, uma invenção pode representar a variação total e absoluta dos problemas ambientais que a humanidade enfrenta hoje. Embora pareça mágico ou inacreditável, já existem várias invenções de produtos e de processamento que estão ajudando a combater, mitigar e eliminar a poluição ambiental, consequentemente, as alterações climáticas. (CHUGÁ PORRAS, 2015)

${ }^{11}$ Eco Patent Common (ECO PC) - criado pelo Conselho Empresarial para o Desenvolvimento Sustentável (WBCSD), propõe a livre troca de patentes a custo zero entre interessados em fazer uso dessas tecnologias na área de sustentabilidade. (http://ecopatentcommons.org/) 
De acordo com Eric L. Lane, é amplamente reconhecido que a inovação em tecnologias verdes será um componente central de qualquer solução para o problema do aquecimento global. Dos veículos legais e regulamentares que promovem a inovação tecnológica, os regimes de propriedade intelectual, particularmente as leis e regras de patentes, são talvez os mais importantes. Historicamente, os governos implementaram sistemas de patentes para criar ou incentivar a indústria a investir recursos financeiros em pesquisa e desenvolvimento de novas tecnologias. Em muitos casos, a exclusividade conferida por uma patente pode proporcionar retorno adequado do investimento para justificar o risco financeiro da pesquisa e desenvolvimento. (LANE, 2012)

Com isso, o autor demonstra que as patentes representam papel fundamental não apenas como incentivo em pesquisa e desenvolvimento, mas também como um poderoso veículo para a parte crítica da inovação, quais sejam, a difusão e emprego de tecnologias verdes.

Em relação à isso, Fernando Almeida assevera:

A criação de inovações sustentáveis envolve prover e estimular visões alternativas do mundo; assegurar o elo entre o desenvolvimento da inovação e seu valor na cadeia produtiva; procurar novas plataformas, assim como aperfeiçoar as já existentes; estimular o empreendedorismo, envolvendo estudantes e profissionais de diferentes gerações; promover pequenos negócios sem perder de vista sua reprodutibilidade para obter ganhos de escala; e, por fim, desafiar os modelos de negócios com cenários alternativos de futuro. (2007, p. 171)

Lane sustenta a importância das patentes verdes como veículos para a implementação de tecnologias limpas. Explica que os produtos e serviços de tecnologia limpa podem ser desenvolvidos por meio de pesquisas e testes, mas não podem ser implementados sem instalações de fabricação para montá-los, desenvolvedores de projetos para construí-los e consumidores para comprá-los e usá-los. O autor refere também que as barreiras à entrada na indústria de tecnologia limpa podem ser elevadas, particularmente no que diz respeito à comercialização de tecnologias verdes, mas que por meio de patentes verdes, empresas de tecnologia limpa podem alavancar sua tecnologia proprietária de várias maneiras para implementar e implementar com êxito suas tecnologias. O foco no licenciamento de tecnologia patenteada para outras empresas permite às empresas contornar certas barreiras à entrada no mercado, como 
construir fábricas, comprar equipamentos e contratar funcionários que de outra forma existiriam em modelos de negócios mais tradicionais. (LANE, 2012)

Diante dos posicionamentos dos autores pesquisados, no que se refere às patentes verdes, à relação entre os direitos de propriedade intelectual e o meio ambiente, corrobora-se com as ideias de Lane, o qual demonstra a importância das patentes verdes na disseminação de tecnologias verdes no Mercado. Entende-se que a proteção às tecnologias ambientalmente amigáveis, por meio das patentes verdes, é uma forma de incentivo ao desenvolvimento de mais tecnologias deste tipo, as quais devem gozar de privilégios e benefícios, já que refletem os anseios de sustentabilidade. Os Programas de Patentes Verdes são uma forma de beneficiar esse tipo de tecnologia, já que aceleram o exame dos pedidos de patentes verdes.

Nesse contexto, quando se oferece a possibilidade de tecnologias verdes contarem com uma proteção jurídica que seja mais célere, ante o quadro de excessiva morosidade das patentes comuns, tal situação funciona como um propulsor da atividade criacionista na área tecnológica ambiental. Essa excessiva morosidade das patentes comuns, acaba por gerar o chamado backlog $^{12}$ das patentes, que é o atraso considerável no exame de patentes.

Sobre o backlog de patentes, Barbosa (2017) referiu em um de seus textos sobre um estudo realizado pelo Centro de Estudos e Debates estratégicos da Câmara dos Deputados, em 2013, o qual dava especial atenção ao problema do backlog. A conclusão da análise feita foi a seguinte:

De qualquer forma, um atraso muito estendido no exame das patentes acaba por causar insegurança jurídica. Insegurança não apenas para os depositantes de patentes, mas também para seus potenciais concorrentes, bem como para a sociedade como um todo. Os depositantes não sabem se terão suas patentes concedidas e, nesse meio tempo (hoje, aproximadamente 10 anos), não sabem se têm ou não direito de uso exclusivo das reivindicações feitas nos pedidos de patentes. Os concorrentes não sabem se podem explorar o objeto do pedido dos depositantes, sem correr risco de serem processados e condenados. E a sociedade perde. Perde porque não sabe se quem explora o objeto da patente tem ou terá realmente direito sobre ela, tampouco se um concorrente pode explorar o mesmo objeto. Se há exploração por parte de um concorrente, pode ser que no dia seguinte uma ordem judicial exija que os produtos sejam retirados do mercado. A população perde. Todos os envolvidos perdem. A insegurança é considerável.

12 Ver: http://www.inpi.gov.br/menu-servicos/patente/consultas-publicas/arquivos/consulta_publica__diretrizes_de_exame_de_pedidos_de_patente___bloco_ii____patenteabilidade.pdf 
Por fim, verifica-se a relevância dos Programas de Patentes Verdes como um estímulo para o desenvolvimento as inovações, uma vez que a rapidez no processo de análise é um incentivador importante à geração de inovações verdes, contribuindo de maneira positiva para a implementação do desenvolvimento sustentável.

Ademais, percebe-se a necessidade de se criar incentivos governamentais à fabricação dos processos e produtos gerados pelas patentes verdes (o que se desdobra na produção e consumo sustentáveis), disponibilizando linhas de financiamento com fomento à pesquisa de tecnologias sustentáveis. Também, podem ser criados incentivos fiscais que diminuam a carga tributária no processo de elaboração e utilização dessas tecnologias verdes, em benefício do meio ambiente.

Tais considerações são apenas o início de importantes discussões que devem ser travadas em relação ao tema, afim de delinear o tratamento dado às patentes verdes como uma ferramenta para a implementação do desenvolvimento sustentável.

\section{Considerações Finais}

Promover a inovação ambientalmente amigável tornou-se uma prioridade fundamental na política ambiental nacional e internacional. Os regimes de propriedade intelectual, particularmente as leis de patentes, são talvez o mais importante dos veículos reguladores que promovem a inovação tecnológica.

Apesar de buscar promover a competitividade no setor de tecnologia verde, o Programa de Patentes Verdes do INPI pode ser extremamente benéfico à sociedade à medida que é implementado, através do programa, a aceleração do exame técnico dos pedidos referentes às tecnologias verdes. Logo, o diferencial estabelecido pelo INPI das patentes verdes em relação às patentes convencionais, está relacionado com o tempo administrativo para análise e concessão ou negativa do pedido patentário. No caso das patentes verdes, o prazo para análise é muito inferior aos pedidos de patentes não verdes.

O incentivo à patenteabilidade de tecnologias verdes reflete o modo de como se quer ver o mundo daqui a alguns anos, já que um sistema que não se preocupa com a esgotabilidade dos recursos naturais, provocando grave degradação ambiental em detrimento do desenvolvimento econômico, está fadado ao comprometimento da sadia qualidade de vida de sua população atual e futura. Logo, as patentes verdes podem 
incentivar as tecnologias posteriores a tomar como base os avanços ambientais proporcionados. Assim, por exemplo, para que a produção e o consumo sejam mais sustentáveis, as tecnologias que os antecedem também devem ser sustentáveis.

\section{Referências das fontes citadas}

ALMEIDA, Fernando. Os desafios da sustentabilidade: uma ruptura urgente. Rio de Janeiro: Elsevier, 2007.

BARBOSA, Denis Borges. A inexplicável política pública por trás do parágrafo único do art. 40 da Lei de Propriedade Industrial. Disponível em: http://www.denisbarbosa.addr.com/arquivos/200/propriedade/inexplicavel_politica_pub lica.pdf Acesso em: 28 de fevereiro de 2017.

BARBOSA, Denis Borges. Patentes, padrões técnicos e Ofertas de licença FRAND em direito brasileiro. Disponível em: http://www.denisbarbosa.addr.com/arquivos/200/propriedade/patentes padros ofertas.p df Acesso em: 28 de fevereiro de 2017.

CANADIAN INTELLECTUAL PROPERTY OFFICE. Expedited examination of patente applications related to green technology. http://www.cipo.ic.gc.ca/eic/site/cipoInternet-Internetopic.nsf/eng/wr02462.html 15 de janeiro de 2017.

CHUGÁ PORRAS, Andrés Wilfrido. Estudios de los programas sobre tecnologías verdes en solicitudes de patentes de invención, y propuesta de un plan piloto al respect. 2015. http://repositorio.puce.edu.ec/handle/22000/8353 Acesso em: 11 de janeiro de 2017.

DECHEZLEPRÊTRE, Antoine; (2013); Fast-tracking Green Patent Applications: An Empirical Analysis; ICTSD Programme on Innovation, Technology and Intellectual Property; Issue Paper No. 37; International Centre for Trade and Sustainable Development, Geneva, Switzerland, www. ictsd.org p. 3.

HALL, Bronwyn H.; HELMERS, Christian. Innovation and diffusion of clean/green technology: can patent commons help? 2011. Disponível em: http://www.nber.org/papers/w16920.pdf Acesso em: 28 jan. 2016. 
INSTITUTO NACIONAL DE PROPRIEDADE INDUSTRIAL (INPI). Exame prioritário "Patentes Verdes" se torna serviço permanente do INPI. Disponível em: http://www.inpi.gov.br/noticias/Patentes\%20Verdes Acesso em: 16 de janeiro de 2017.

. Indicadores quantitativos do projeto piloto. Disponível em:

http://www.inpi.gov.br/menu-

servicos/patente/arquivos/PatentesVerdes_14julho2015_pptx.pdf/view Acesso em 17 de janeiro de 2017.

Patentes Verdes. Disponível em: http://www.inpi.gov.br/menuservicos/patente/patentes-verdes-v2.0 Acesso em: 01 de novembro de 2016.

- Resolução $\mathbf{n}^{\mathbf{0}} 83$ de 09 de abril de 2013. Disponível em: http://www.inpi.gov.br/legislacao-arquivo/docs/resolucao_83-2013_-

_prorrogacao_patentes_verdes.pdf Acesso em: 15 de janeiro de 2017.

. Resolução $\mathbf{n}^{\circ} 131$ de 15 de abril de 2014. Disponível em: http://www.inpi.gov.br/menu-

servicos/patente/arquivos/resol131_3a_fase_pv_rpi2260.pdf Acesso em: 15 de janeiro de 2017.

Resolução $\mathbf{n}^{\circ} 145$ de 17 de março de 2015. Disponível em: http://www.inpi.gov.br/menu-

servicos/patente/resolucaoprorrogacaopv_resol145_2015.pdf Acesso em: 15 de janeiro de 2017

. Resolução $\mathbf{n}^{0}$ 175, de 05 de novembro de 2016. Disponível em: http://www.inpi.gov.br/menu-servicos/arquivos-

dirpa/Resoluon1752016_Patentesverdes_21112016julio_docx.pdf

Resolução PR $\mathbf{n}^{0} 283$ de 02 de abril de 2012. Disponível em: http://ld2.ldsoft.com.br/siteld/arq_avisos/Comunicados_Patentes1_RPI_2154.pdf Acesso em: 15 de janeiro de 2017.

INTELLECTUAL ASSET MANAGEMENT. Accelerated examination now available for green-tech patente applications - International Report. http://www.iammedia.com/reports/Detail.aspx?g=a663e3ab-7973-4930-b8cd-0d637fb684e3 16 de janeiro de 2017.

INTELLECTUAL PROPERTY OFFICE (United Kingdom), UK ’Green 'inventions to get fast-tracked through patente system, http:/www.ipo.gov.uk/about/press/pressrelease/press-release-2009/press-release-20090512.htm, 12 de janeiro de 2017. 
INTELLECTUAL PROPERTY OFFICE AUSTRALIA. Fast tracking patentes for green technology, https://www.ipaustralia.gov.au/patents/applying-patent/standardpatent-application-process/examination-standard-patent/expedited-examinationstandard-patents 13 de janeiro de 2017.

ISRAEL PATENT OFFICE. Green applications. http://www.justice.gov.il/En/Units/ILPO/Departments/Patents/Pages/Greenapplications.aspx 15 de janeiro de 2017. JAPAN PATENT ATTORNEYS ASSOCIATION. Accelerated (appeal) examination for green technology patente applications, http://www.jpaa.or.jp/english/whatsnew/pdf/green_technology_patent.pdf, 13 de janeiro de 2017.

KOREAN INTELlECtUAL PROPERTY OFFICE. Annual Report 2009. http://www.kipo.go.kr/upload/en/download/annualreport_2009.pdf 13 de janeiro de 2017.

LANE, Eric L. Building the Global Green Patent Highway: A Proposal For International Harmonization of Green Technology Fast Track Programs, 27 Berkeley Tech. L.J. (2012). Available at: http://scholarship.law.berkeley.edu/btlj/vol27/iss2/5 )

Clean Tech Intellectual Property, Oxford University Press, Inc., New York, 2011

Clean Tech Reality Check: Nine International Green Technology Transfer Deals Unhindered by Intellectual Property Rights, 26 SANTA ClaRA High TeCH. L.J. 533 (2012). Available at: http://digitalcommons.law.scu.edu/chtlj/vol26/iss4/2 Speed Bumps Emerge on KIPO Green Tech Fast Track, GREEN PATENT BLOG. (Oct. 23, 2011) http://www.greenpatentblog.com/2011/10/ 13 de janeiro de 2017.

LEFF, Enrique. Saber ambiental: sustentabilidade, racionalidade, complexidade e poder. Petrópolis: Vozes, 2001.

ONU. Transformando Nosso Mundo: A Agenda 2030 para o Desenvolvimento Sustentável. Disponível em: http://www.pnud.org.br/Docs/TransformandoNossoMundo.pdf Acesso em: 25 de março de 2016.

REIS, Patricia Carvalho dos. [et. Al.] Programa das Patentes Verdes no Brasil: Aliança Verde entre o Desenvolvimento Tecnológico, Crescimento Econômico e a 
Degradação

Ambiental.

Disponível

em:

http://www.altec2013.org/programme_pdf/1518.pdf Acesso em: 25 de março de 2016.

RICHTER, Fernanda Altvater. As patentes verdes e o desenvolvimento sustentável. In:

Revista Meio Ambiente e Sustentabilidade. vol. 6, n.3, p. 383 - 398. jul - dez 2014.

SANTOS, Nivaldo dos; OLIVEIRA, Diego Guimarães de. A patenteabilidade de tecnologias verdes como instrumento de desenvolvimento sustentável. In: Revista Jurídica. vol. 4, n.37, p. 294-310. out - dez 2014. Disponível em: http://revista.unicuritiba.edu.br/index.php/RevJur/article/view/1051/738 Acesso em: 25 de março de 2016.

UNITED STATES PATENT AND TRADEMARK OFFICE (USPTO). Expansion and Extension of the Green Technology Pilot Program. Federal Register, v. 75, n. 217, November 10, 2010/Notices. https://www.gpo.gov/fdsys/pkg/FR-2010-11-10/pdf/201028394.pdf 14 de janeiro de 2017.

\section{$\begin{array}{llll}\text { Green } & \text { Petition } & \text { Report } & \text { Summary. }\end{array}$}

https://www.uspto.gov/sites/default/files/patents/init_events/green_report_summary201 20426.pdf 14 de janeiro de 2017.

- Green Technology Pilot Program - CLOSED.

https://www.uspto.gov/patent/initiatives/green-technology-pilot-program-closed 14 de janeiro de 2017. 